\title{
2 Fast Delivery of life saving medical supplies 3 in rural areas of Ethiopia
}

4

5 Brhanu Fentaw Znabu (Department of Biomedical Engineering, Hawassa Institute of

6 Technology, Hawassa University, Hawassa, Ethiopia)

7 Amanuel Adem Negero

$8 \quad$ Lenchio Gudina Begna

$9 \quad$ Sisay Tamene Tsegaye

10 Debelo Oljira Hinaw (Ambo University, Ambo, Ethiopia)

11

12 Corresponding Author: Brhanu Fentaw Znabu (Email address: brhanufenbme@gmail.com) 13 


\section{Abstract}

Background: Ethiopia's maternal mortality rate is among the highest in the world with 470 deaths per 100,000 live births. Every year post-partum hemorrhage (PPH) remains the leading cause of maternal mortality in Ethiopia. The problem is worse in the rural setting where there are not proper facilities and trained health workers to administer injectable medicine. Currently, the methods used by health centers in rural areas include referring the patient to the nearest hospital within a short period of time even though most of patients die in the ambulances without reaching the hospitals in nearby.

Method: In this project, the design of rotary-wing unmanned aerial vehicle (UAV) with thermoelectric cold-box system is proposed. The temperature of blood bag is controlled by a thermoelectric cooler working based on the Pieter effect. The blood is transported to rural health centers through UAV, and the blood containing box will release it from higher altitudes using

27 servo dropping mechanism.

Results: The prototype was built and undergone through different iteration process. The proposed device was tested for safety, delivery time, bioavailability, range of operation, weight of the package and durability. For this design, the drone was flown a distance of 10km with less than 15 minutes while 100 meters above the ground.

32 Conclusion: The proposed project has a clinical significance such as saving the lives of mothers 33 and the child. Through the design of a UAV, the transportation of medical and biological component is feasible. The use of UAVs for medical supply delivery will considerably reduce the number of people admitting to the hospital and, therefore, minimizes the cost of medical services that comes with hospitalization. 


\section{Background}

40 In Sub-Saharan Africa, more than 250,000 women die each year due to complications related to 41 pregnancy or child birth [1,2]. According to WHO (world health organization) report, Ethiopian's

42 maternal mortality rate is recorded as one of the highest in the world with 470 deaths with 100,000

43 live births [ 3]. Direct and indirect causes can contribute to the maternal death. Hemorrhage, 44 infection, hypertensive disorders and obstructed labour are considered as direct causes while the

45 indirect one includes concurrent diseases that are complicated during pregnancy [1]. Postpartum 46 hemorrhage (PPH) is defined as the loss of more than $500 \mathrm{ml}$ blood after delivery $[4,5,8]$. However,

47 for the clinical purpose any amount of blood loss that could potentially result in hemodynamic 48 instability should be considered PPH [5]. It remains to be the leading cause of maternal mortality 49 in developing countries like Ethiopia [3]. The problem is worse in resource poor setting where 50 there are not proper facilities, such as refrigerator, and skilled healthcare givers to administer 51 injectable uterotonics, which are the standard treatment for PPH $[3,6,7]$. Blood transfusion can be 52 a life-saving medical intervention [10,11], and a vital reason for improving blood transfusion is to 53 reduce maternal mortality rate. However, it is the least available service in district hospital, 54 Ethiopia [3]. In African countries, one of the reasons identified is the challenge to provide access 55 to blood due to infrastructure limitation [3.9]. Insufficient and unreliable cold storage capacity to 56 accommodate the different types of blood and other medications required has been reported as a 57 challenges [12].

58 To treat mother's suffered from postpartum hemorrhage and patient with a severe anemia, several 59 techniques have been used. Of these oxytocin is a standard medical therapy that is routinely 60 administered for prevention and treatment of PPH [3,6,7,13,14]. However, the cost and the need 61 for a skilled person to inject could compromise its acceptability [3]. Misoprostol has also been 
62 used as both prevention and treatment of PPH. Although the delivery of misoprostol reduces

63 maternal mortality rate and could have advantages as it is easy to use and relatively cheap, it has

64 been reported relatively less effective than oxytocin [3, 15-18]. The methods, currently, used by

65 health centers in rural Ethiopia includes referring the patient to the nearest hospital within a short

66 period of time $[19,27]$. However, these solutions create a problem most of the time because, the

67 roads from rural areas to urban hospitals are not always as stable physically and provide a speedy transportation to patient as the result of this patient's die in the ambulances without reaching the

69 hospitals in nearby. The other problem with the existing solution is mothers who delivered child 70 safely by using medication have a high risk of developing severe anemia which requires immediate

71 blood transfusion. Although the medications provide short-term solutions blood transfusion is 72 must to solve the problem reliably. In Ethiopia, blood is not stored at rural health center because 73 of inadequate blood, unavailability of material for the proper storage and unavailability of 24-hour 74 electricity [3]. Also transporting blood and medical supplies by road is often a long and difficult 75 process in Ethiopia because of limitation of infrastructure such as road, and number of ambulances 76 [20]. These all limitation makes any health center in Ethiopia not to make any blood transfusion 77 for birth giving mothers. In this project unmanned aerial vehicle with its own cooling system is 78 proposed. Using a modified drone to implement a medical supply delivery system which carries 79 blood first-aid equipment, medicine and other medical supplies, Ethiopian's health care system 80 can eliminate the unnecessary burdens that families face and at the same time play a vital role in 81 the development of technology in the medical arena.

\section{Methods}

83 Proposed Design 
84 The design can be classified into two major parts based on the functions it provides. The first part

85 is the unmanned aerial vehicle part which is designed to carry a payload to remote areas with automated navigation. The second design is the design of storage system called the cold-box for

87 the safety of the blood transported the system contains a cooling unit and automatic temperature controlling system to carry bloods, vaccines and other medical supplies at the required temperature. The unmanned aerial vehicle consists of both software and hardware parts. The most common hardware components involved in prototyping include GPS (Global positioning system)

91 and compass, flight control unit, data transmission module, data receiving module, remote 92 controller, DC (direct current) motors and on screen display. Using these components, the UAV's 93 body design was developed to allow for an appropriate implementation of each component while 94 carefully considering the weight, the balance, and the drone's overall center of mass. The most important electrical component used for prototyping is flight controller. It is essentially the brains of UAV, which allows the drone to maintain balance, and it does this by gathering data through 97 sensors and computing for the necessary changes for the motors. Figure 1 show functional block diagram of the rotary-wing unmanned aerial vehicle and with thermoelectric cooler. The list of 99 components used for designing cold box includes thermoelectric cooling system, LM35 temperature sensor, $12 \mathrm{~V}$ battery and Arduino Uno microcontroller. Figure 2 shows the flow chart 101 of the cold-box design. The thermoelectric cooler designed operates with LM35 temperature 102 sensor and DC fan to control the storage temperature of the cold-box. The blood during 103 transportation needs to be maintained at standard temperature range to maintain at a normal 104 condition. The LM35 senses the temperature of the cold box and compares with the standard 105 temperature stored by the UAV. The thermoelectric cooler then reduces the temperature of the 106 cold-box based on the temperature range measured by the LM35 temperature sensor. 


\section{Results}

108

\section{Final design}

The design of the UAV and the cold box prototype has gone through different iteration processes to come up with the final working design of our project. In addition to this changes have been made to the design of our project. The design team modified the first proposed initial design until designing the final design. Figure 3 shows parts of the final design (from left to right: from top to bottom). The following components has been used in the final design: S500 Multi-Rotor AirFrame, Pixhawk Flight controller, X8R Receiver, GPS, Taranis transmitter, propeller, safety switch, Arduino UNO, Brushless DC motor, Lipo Battery, Lightweight material to make the package, servo motor, servo controller, DC fan, and LCD (liquid crystal display). Figure 4 shows the final design of cold box and constitute in the quadcopter drone. Functional testing, electrical safety and performance testing have been done in order to verify whether the design criteria and specification were fulfilled. Table 1 shows the test results (see at the end of the conclusion part)

\section{Discussion}

In Ethiopia, mothers who live in rural areas suffering from bleeding related complications even though the government has taken serious measurements. Medications, oxytocin and misoprostol, have been used for the management and prevention purpose [13-18]. However, they might bring severe anemia which requires immediate blood transfusion. This indicates that a fast and simple blood delivery mechanism is needed. In this study a device can deliver blood and other critical medical supplies to rural areas of Ethiopia is designed with appropriate controlling temperature mechanism. Drone technology is increasingly being used for medical purposes such as transporting blood, vaccines and organs in some countries [24]. In Rwanda, the collaboration of the government 
with drone company (Zipline) makes it possible to deliver blood from the center to its rural areas. However, the designed device has no any cooling system which maintains the blood at optimum temperature, it has been used for a short trip [21, 22]. In the united states, manned aircraft was also proposed to reduce maternal mortality rate by delivering blood to critical access hospitals. However, risks to the flight crews travelling in remote areas was a great concern [23]. In 2016, pilot drone project was conducted and successfully delivered drugs and laboratory samples to rural places in Madagascar. Although it was a promising innovation, limited flight range, due to lack of cooling system placed inside the drone, was reported as a limitation [25]. The major challenges in the use of medical drone is the legal permission from Aviation Authorities in some countries like India [24]. Mostly bloods being delivered by the drone was jeopardize due to temperature difference during the flight [26]. So there must be appropriate temperature management in drone payload compartments. Our method provides reliable blood delivery mechanism with temperature controlled device. While the designed device meets desired objectives, it delivers medical supplies to a short distance. This is only due to low battery capacity which can be replaced by another powered battery that makes it possible to long distance travel with longer periods. On the other hand, unmanned aerial vehicle implemented in both Rwanda and Madagascar couldn't travel longer distance with keeping medical products at desired temperature for safety $[21,22,25]$. The proposed design provides high level of safety. It can also be used for transporting organs for transplantation.

\section{Conclusion}

In conclusion, this project provided insight on the feasibility of the objectives set out to be achieved. The design team successfully designed and built a drone with an arm attachment (for the cold box) to enhance the successful transportation of blood and other critical medical supplies. 
152 Thus, the design and testing of the drone successfully demonstrated the concept feasibility of

153 implementing blood and other critical medical supplies delivery drones in the health care system

154 of Ethiopia.

155 Table 1: design objectives and their test results

\begin{tabular}{|c|c|c|c|c|c|}
\hline No & Feature to be tested & Input & Method & $\begin{array}{l}\text { Design } \\
\text { specification }\end{array}$ & Result \\
\hline 1. & Delivery Time & $\begin{array}{l}\text { Enumerating } \\
\text { the time }\end{array}$ & $\begin{array}{l}\text { Measuring } \\
\text { the time } \\
\text { using timer }\end{array}$ & $\begin{array}{l}\text { Maximum of } \\
10 \pm 5 \text { delivery } \\
\text { time }\end{array}$ & $\begin{array}{l}\text { The time is in } \\
\text { the range }\end{array}$ \\
\hline 2. & Safety & $\begin{array}{l}\text { The storage } \\
\text { temperature }\end{array}$ & $\begin{array}{l}\text { Sensor, the } \\
\text { LM35 } \\
\text { temperature } \\
\text { sensor }\end{array}$ & $2^{\circ} \mathrm{C}-8^{\circ} \mathrm{C}$ & $\begin{array}{l}\text { The cooling } \\
\text { of the } \\
\text { thermoelectric } \\
\text { cooler }\end{array}$ \\
\hline 3. & Weight of the package & $\begin{array}{l}\text { The package } \\
\text { loaded to the } \\
\text { drone }\end{array}$ & $\begin{array}{l}\text { Measuring } \\
\text { the weight of } \\
\text { the drone }\end{array}$ & $\begin{array}{l}\text { The weight } \\
\text { of the } \\
\text { payload } \\
\text { should be }< \\
2.4 \mathrm{Kg}\end{array}$ & $\begin{array}{l}\text { The weight }< \\
2.4 \mathrm{Kg}\end{array}$ \\
\hline 4. & Range of operation & $\begin{array}{l}\text { The distance } \\
\text { traveled by } \\
\text { the drone }\end{array}$ & $\begin{array}{l}\text { Measuring } \\
\text { the speed and } \\
\text { time of flight }\end{array}$ & $\mathrm{Up}$ to $10 \mathrm{Km}$ & $\begin{array}{l}\text { Operating } \\
\text { range is } \\
\text { below } 10 \mathrm{Km}\end{array}$ \\
\hline 5. & Bioavailability & $\begin{array}{l}\text { The storage } \\
\text { temperature } \\
\text { of the UAV }\end{array}$ & $\begin{array}{l}\text { The } \\
\text { measurement } \\
\text { of the } \\
\text { temperature } \\
\text { sensor }\end{array}$ & $\begin{array}{l}\text { The material } \\
\text { from which } \\
\text { the cold box } \\
\text { is } \\
\text { manufactured }\end{array}$ & $\begin{array}{l}\text { The reduced } \\
\text { environmental } \\
\text { effect on the } \\
\text { cold box }\end{array}$ \\
\hline 6. & Durability & $\begin{array}{l}\text { Physical } \\
\text { analysis of } \\
\text { the drone }\end{array}$ & $\begin{array}{l}\text { Analyzing } \\
\text { and } \\
\text { calculating } \\
\text { the service } \\
\text { life of the } \\
\text { drone }\end{array}$ & $\begin{array}{l}\text { The strength } \\
\text { of the } \\
\text { different } \\
\text { components }\end{array}$ & $\begin{array}{l}\text { The } \\
\text { components } \\
\text { are good } \\
\text { quality and } \\
\text { light weight }\end{array}$ \\
\hline
\end{tabular}

156

157 Abbreviations

158 UAV: Unmanned aerial vehicle; GPS: Global positioning system; PPH: postpartum hemorrhage;

159 WHO: World Health Organization; DC: Direct current; LCD: Liquid crystal display

\section{Acknowledgments}


161 We would like to acknowledge Dr. Timothy Kwa and Mr. Mohammed Aliy for their valuable

162 advises and guidance

\section{Authors' contribution}

164 BF, AA, LG, ST, DO are investigators of this study and they conceptualized, designed, and

165 implemented. All authors contributed to the preliminary study, the design, prototyping and

166 testing. This study was initiated by LG. The article was drafted by BF, taking into account the

167 comments and suggestions of the coauthors. All authors read and approved the final manuscript.

\section{Funding}

169 All the authors dedicated their additional working hour to develop this paper with no specific

170 grant from any funding agency

171 Availability of data and materials

172 Not applicable

\section{Ethics approval and consent to participate}

174 Not applicable

\section{Consent for publication}

176 Not applicable

177 Competing interests

178 The authors declare that they have no competing interests. 
1. Alvarez, J.L., Gil, R., Hernández, V. and Gil, A., 2009. Factors associated with maternal mortality in Sub-Saharan Africa: an ecological study. BMC public health, 9(1), p.462.

2. World Health Organization, 2010. Maternal mortality in 2005. Estimates developed by WHO, UNICEF, UNFPA, and the World Bank.

3. Hddis, M. and Woyessa, A., 2012. Prevention of Postpartum Hemorrhage in Rural Ethiopia (SURE policy brief). Addis Ababa: Technology Transfer and Research Translation Directorate, Ethiopian Health and Nutrition Research Institute.

4. Anderson, J.M. and Etches, D., 2007. Prevention and management of postpartum hemorrhage. American Family Physician, 75(6), pp.875-882.

5. Leduc, D., Senikas, V., Lalonde, A.B., Ballerman, C., Biringer, A., Delaney, M., Duperron, L., Girard, I., Jones, D., Lee, L.S.Y. and Shepherd, D., 2009. Active management of the third stage of labour: prevention and treatment of postpartum hemorrhage. Journal of obstetrics and gynaecology Canada, 31(10), pp.980-993.

6. Prata, N., Gessessew, A., Abraha, A.K., Holston, M. and Potts, M., 2009. Prevention of postpartum hemorrhage: options for home births in rural Ethiopia. African Journal of Reproductive Health, 13(2).

7. Lalonde, A., 2013. Prevention and treatment of postpartum hemorrhage in low-resource settings. Obstetric Anesthesia Digest, 33(3), pp.136-137.

8. Oyelese, Y. and Ananth, C.V., 2010. Postpartum hemorrhage: epidemiology, risk factors, and causes. Clinical obstetrics and gynecology, 53(1), pp.147-156.

9. Bloch, E.M., Vermeulen, M. and Murphy, E., 2012. Blood transfusion safety in Africa: a literature review of infectious disease and organizational challenges. Transfusion medicine reviews, 26(2), pp.164-180.

10. van Hulst, M., Sibinga, C.T.S. and Postma, M.J., 2010. Health economics of blood transfusion safety-focus on sub-Saharan Africa. Biologicals, 38(1), pp.53-58.

11. Klein, H.G., Spahn, D.R. and Carson, J.L., 2007. Red blood cell transfusion in clinical practice. The Lancet, 370(9585), pp.415-426. 
12. World Health Organization, Geneva. The blood cold chain: Guide to the selection and procurement of equipment and accessories. November 2002. P.1

13. Dildy lii, G.A., 2002. Postpartum hemorrhage: new management options. Clinical obstetrics and gynecology, 45(2), pp.330-344.

14. Van Dongen, P.W.J., Van Roosmalen, J., De Boer, C.N. and Van Rooij, J., 1991. Oxytocics for the prevention of post-partum haemorrhages. Pharmaceutisch Weekblad, 13(6), pp.238243.

15. Mathai, M., Gülmezoglu, A.M. and Hill, S., 2007. Saving women's lives: evidence-based recommendations for the prevention of postpartum haemorrhage.

16. Who guidelines for the management of post-partum hemorrhage and retained placenta. World health organization 2009. P.8.

17. Çalişkan, E., Meydanli, M.M., Dilbaz, B., Aykan, B., Sönmezer, M. and Haberal, A., 2002. Is rectal misoprostol really effective in the treatment of third stage of labor? A randomized controlled trial. American journal of obstetrics and gynecology, 187(4), pp.1038-1045.

18. Gerstenfeld, T.S. and Wing, D.A., 2001. Rectal misoprostol versus intravenous oxytocin for the prevention of postpartum hemorrhage after vaginal delivery. American journal of obstetrics and gynecology, 185(4), pp.878-882.

19. Prata, N., Gessessew, A., Abraha, A.K., Holston, M. and Potts, M., 2009. Prevention of postpartum hemorrhage: options for home births in rural Ethiopia. African Journal of Reproductive Health, 13(2).

20. CNM, L.S., Buffington, S.T. and Haileyesus, D., 2004. The American College of NurseMidwives' Home-Based Lifesaving Skills Program: A Review of the Ethiopia Field Test. The Journal of Midwifery \& Women's Health, 49(4), pp.320-328.

21. Rutkin, A., 2016. Blood delivered by drone.

22. Glauser, W., 2018. Blood-delivering drones saving lives in Africa and maybe soon in Canada.

23. Thiels, C.A., Aho, J.M., Zietlow, S.P. and Jenkins, D.H., 2015. Use of unmanned aerial vehicles for medical product transport. Air medical journal, 34(2), pp.104-108. 
24. Laksham, K.B., 2019. Unmanned aerial vehicle (drones) in public health: A SWOT analysis. Journal of family medicine and primary care, 8(2), p.342.

25. Wurbel, H., 2017. Framework for the evaluation of cost-effectiveness of drone use for the last-mile delivery of vaccines.

26. Ling, G. and Draghic, N., 2019. Aerial drones for blood delivery. Transfusion, 59(S2), pp.1608-1611.

27. Nureye, D. and Tekalign, E., 2019. Opportunities and Challenges of Blood Donation and Blood Therapy in Ethiopia. Health Sciences, 8(8), pp.122-127. 